\title{
Influence of Fly Ash, Bottom Ash, and Light Expanded Clay Aggregate on Concrete
}

\author{
S. Sivakumar ${ }^{1}$ and B. Kameshwari ${ }^{2}$ \\ ${ }^{1}$ NPR College of Engineering and Technology, NPR Nagar, Natham, Dindigul, Tamil Nadu 624401, India \\ ${ }^{2}$ Ratnavel Subramaniam College of Engineering and Technology, Dindigul, Tamil Nadu 624005, India
}

Correspondence should be addressed to S. Sivakumar; sivakumars0781@gmail.com

Received 29 October 2014; Accepted 12 December 2014

Academic Editor: Aiguo Xu

Copyright (c) 2015 S. Sivakumar and B. Kameshwari. This is an open access article distributed under the Creative Commons Attribution License, which permits unrestricted use, distribution, and reproduction in any medium, provided the original work is properly cited.

\begin{abstract}
Invention of new methods in strengthening concrete is under work for decades. Developing countries like India use the extensive reinforced construction works materials such as fly ash and bottom ash and other ingredients in RCC construction. In the construction industry, major attention has been devoted to the use of fly ash and bottom ash as cement and fine aggregate replacements. In addition, light expanded clay aggregate has been introduced instead of coarse aggregate to make concrete have light weight. This paper presents the results of a real-time work carried out to form light weight concrete made with fly ash, bottom ash, and light expanded clay aggregate as mineral admixtures. Experimental investigation on concrete mix $\mathrm{M}_{20}$ is done by replacement of cement with fly ash, fine aggregate with bottom ash, and coarse aggregate with light expanded clay aggregate at the rates of $5 \%, 10 \%$, $15 \%, 20 \%, 25 \%, 30 \%$, and $35 \%$ in each mix and their compressive strength and split tensile strength of concrete were discussed for 7,28 , and 56 days and flexural strength has been discussed for 7, 28, and 56 days depending on the optimum dosage of replacement in compressive strength and split tensile strength of concrete.
\end{abstract}

\section{Introduction}

High performance concrete indicates an exceptional form of concrete endowed with astonishing proficiency and strength essentials which are unequipped with periodical assessment on a regular basis by way of traditional materials and standard mixing, placing, and curing techniques [1]. Ordinary Portland cement (OPC) has grabbed an unenviable and undefeatable position as a significant material in the generation of concrete and meticulously releases its designed obligation as an extraordinary binder to join all the gathered materials. With the purpose of attaining, there is a dire need of the burning of mammoth measure of fuel and rot of limestone [2]. A few grades of ordinary Portland cement (OPC) are accessible tailor made to suit the particular nation code categorization. In this respect, Bureau of Indian Standard (BIS) exquisitely does the capacity of categorizing three separate grades of OPC, for example, 33,43 , and 53 , which have chronically been widely utilized in construction industry [3]. The strength, sturdiness, and different attributes of concrete rely on the properties of its ingredients, the proportion of the mix, the strategy of compaction, and different controls amid placing, compaction, and curing [4]. Concrete containing wastes can help construction manageable quality and contribute to the advancement of the civil engineering region by employing industrial waste, minimizing the utilization of natural assets, and producing more effective materials [5]. The Portland cement concrete resorts to the employment of fly ash when the loss-on-ignition (LOI) qualities fall inside the area of $6 \%$. The fly ash is home to the crystalline and amorphous components together with unburnt carbon. It grasps differing measures of unburnt carbon, which is prone to reach the tune of $17 \%$ [6]. Fly ash is regularly alluded to as pond ash and over the long haul the water is permitted to drain away. Both techniques viably prompt to dumping of the fly ash in landfills on open land. The chemical composition of fly ash remains changes relying on the type of coal utilized as a part of combustion, combustion conditions, and evacuation productivity of air contamination control device [7]. The effect of fly ash substance and substitution of trampled sand 
stone total with concrete squandrs and marble squanders employed prefabricated concrete interlocking squares [8]. With an eye on the power of concrete edifices, modern concrete methodology set down extraordinary steps to chop down summit and differential temperatures by deploying materials with the minimized level of release of heat to steer clear of or then again bring down thermal splitting prompting the prevention of the decomposition of the concrete [9]. Production of concrete is done in exceedingly high and imperceptibly low temperatures of concrete to understand the workability and compressive quality [10]. The statistical model and the kinetic property of flexural, breaking tensile furthermore modulus of versatility as per the compressive stability stemmed from the unwarranted coefficient of correlation [11]. Concrete generated out of minute total and superior void ratio is known to be enriched with a brilliant expertise to exile the materials [12]. In India, the power division focused around coal based thermal power stations produces a colossal quantity of fly ash assessed around 11 crore tonnes every annum. The consumption of fly ash is assessed to be around $30 \%$ for the purpose of various engineering properties essentials [13]. Ignition of coal to deliver power in a boiler yields around $80 \%$ of the unburned material or ash, which is entrained in the flue gas and is entrapped and reclaimed in the shape of fly ash. The residual $20 \%$ of the ash helps dry base ash [14]. At the point when pulverized coal is blazed in a dry bottom boiler, around 80 to $90 \%$ of the unburned material or ash is entrained in the flue gas and is trapped and recovered as fly ash. The residual 10$20 \%$ of the ash is indicated to dry bottom ash, sand size, material which is assembled in water-filled containers at the base of the furnace [15]. Coal bottom ash in concrete is created by the method of fractional, almost-aggregate, and total substitution of fine aggregates in concrete [16]. On the other hand, lightweight concrete is awkward to make a case belong to a unique category material. However, LWC (light weight concrete) has clear edges, and the plunge in the total expense created by the lower dead loads is constantly overshot by the raised production outlay [17]. As a matter of fact, lightweight concrete has surfaced as the agreeable favorite as against the standard concrete in the perspective of a multitude of unrivaled attributes. The dip in dead weight generally brings about cutbacks in production outlay [18]. The selfcompacting normal weight aggregate concrete (SCNC) is to be the favorite for the purpose of development. The surge in the construction expense of SCLC fares positively with that for SCNC [19]. Lightweight aggregate concrete deadweight is assessed to be around 15\% 30\% lighter than standard concrete, which sufficiently fulfills the mechanical attributes that roadway support requires on the specified density degree [20]. Rising utilization of lightweight concrete (LWC) brought the requirement for the artificial lightweight total production, which may be accomplished by cold bonding assembling methodology. Production of artificial fly lightweight aggregates with cold bonding process needs much less energy consumption when contrasted with sintering [21]. Lightweight concrete made with natural or artificial lightweight aggregates is accessible in numerous parts of the world. It can be utilized as a part of creating concrete in an extensive variety of unit weights and suitable qualities for different applications [22]. Lightweight aggregates concrete livens up its potency to thwart nearby harm activated by ballistic loading. Lower modulus of flexibility and higher tensile strain limit outfits lightweight concrete opposite standard weight concrete with superior impact resistance [23]. Light concrete material is more and more prescribed by the builders to reach a supportable improvement due to its great strength and thermal properties [24]. The adhesive strength is accomplished from solidity in the binder and interlocking traits of the aggregates, which are constantly focused around angularity, levelness, and extension [25]. Light expanded clay aggregate (LECA), generally, includes tiny, lightweight, bloated particles of burnt clay. The hundreds and thousands of tiny, air-filled depressions successfully empower LECA with its sterling strength and thermal insulation qualities. The average water absorption of LECA total $(0-25 \mathrm{~mm})$ is thought to associate with 18 percent of volume in saturated status amid the time of 3 days. The ordinary Portland cement (OPC) is partially substituted by the fly ash, fine aggregate interchanged by bottom ash, and coarse aggregate supplanted by light expanded clay aggregate (LECA) by weights of $5 \%, 10 \%, 15 \%, 20 \%, 25 \%, 30 \%$, and $35 \%$, separately. The compressive strength, split tensile strength, and flexural strength are successfully assessed by means of determined input values in concurrent investigation.

\section{Experimental Program}

The objective of the work is to evaluate the compressive strength (CS), split tensile strength (STS), and flexural strength (FS) of the concrete. In this concrete mix, ordinary Portland cement $\left(\mathrm{OPC}_{43 \text { grade }}\right)$ is replaced by fly ash, the fine aggregate is replaced by bottom ash, and the coarse aggregate is replaced by light expanded clay aggregate (LECA) by weights of $5 \%, 10 \%, 15 \%, 20 \%, 25 \%, 30 \%$, and $35 \%$, respectively. For increasing the strength in cement, these materials are to be added. In the experimental investigation, the concrete cube or cylinder is used to analyze the properties of the concrete with all materials. Each weight (5\%,10\%, 15\%, $20 \%, 25 \%, 30 \%$, or $35 \%$ ) of a material conducted the test on 7 days, 28 days, and 56 days. The parameters involved in evaluating the performance of concrete are compressive strength (CS), split tensile strength (STS), and flexural strength (FS) that are attained from real time experiments. Then finding the flexural strength has been discussed for 7, 28, and 56 days depending on the load for the optimum dosage of replacement in compressive strength and split tensile strength of concrete.

2.1. Materials Used. Names of materials used in this research and their performance are listed in this section. The resources are ordinary Portland cement, fly ash, bottom ash, fine aggregate, coarse aggregate, and light expanded clay aggregate (LECA).

2.1.1. Ordinary Portland Cement. Ordinary Portland cement is the basic form of cement where $95 \%$ of it is clinker and 


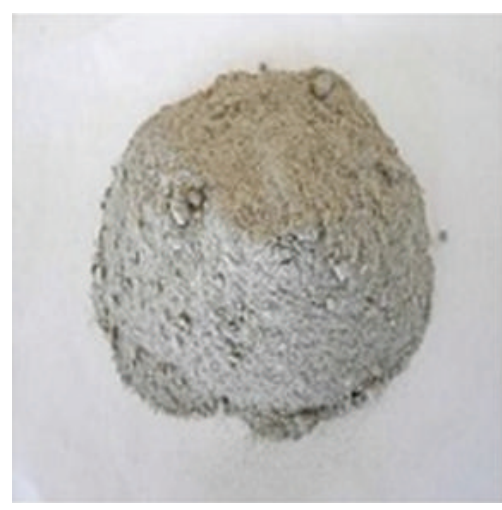

(a) Fly ash

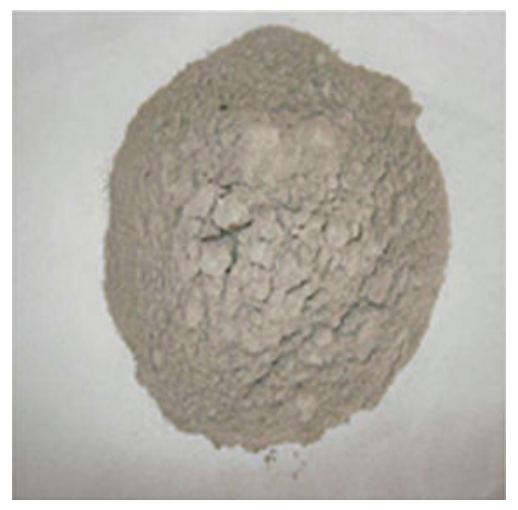

(b) Bottom ash

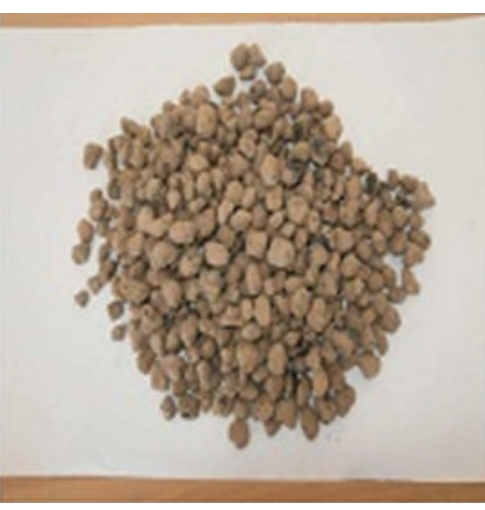

(c) LECA

FIGURE 1: Materials.

$5 \%$ is gypsum which is added as an additive to enhance the setting time of the cement to a workable 30 minutes odd or so. Gypsum controls initial setting time of the cement. If gypsum is not added, cement would be set as soon as water is added in cement. Different grades $(33,43,53)$ of OPC have been classified by the Bureau of Indian Standards (BIS). It is manufactured in larger quantities when compared with the other types of cement and it is admirably suited for use in general concrete construction where there is no exposure to sulphates in the soil or in ground water. In this research, the cement $\left(\mathrm{OPC}_{43 \text { grade }}\right)$ that has a specific gravity of 3.15 and initial and final setting times of the cement of 50 minutes and 450 minutes has been used.

2.1.2. Fly Ash. The most common type of coal-burning furnace in the electric utility industry, about $80 \%$ of the unburned material or ash, is entrained in the flue gas and is captured and recovered as fly ash. Fly ash was collected from Thoothukudi Thermal Power Plant, Tamil Nadu, India. The increasing scarcity of raw materials and the urgent need to protect the environment against pollution have accentuated the significance of developing new building materials based on industrial waste generated from coal fired thermal power station which is creating unmanageable disposal problems due to its potential to pollute the environment. As the cost of disposing of fly ash continues to rise, strategies for the recycling of fly ash are environmentally and economically critical. For the source materials the two emerging areas for the recycling of coal fly ash are used as shown in Figure 1(a).

2.1.3. Bottom Ash. The remaining $20 \%$ of the unburned material is collected at the bottom of the combustion chamber in a water-filled hopper and is removed by means of highpressure water jets to a decanting basin for dewatering and is recovered as bottom ash as shown in Figure 1(b). Coal bottom ash was obtained from Thoothukudi Thermal Power Plant, Tamil Nadu, India. The fly ash was obtained directly from the bottom of the electrostatic precipitator into a sack because of its powdery and dusty nature, while the coal bottom ash is transported from the bottom of the boiler to an ash pond as liquid slurry where the sample was collected. Bottom ash is lighter and more brittle and it is dark gray material with a grain size similar to that of sand.

2.1.4. Fine Aggregate. According to the Indian standards natural sand is a form of silica $\left(\mathrm{SiO}_{2}\right)$ that has maximum particle size of $4.75 \mathrm{~mm}$ and it was used as fine aggregate. The minimum particle size of fine aggregate is $0.075 \mathrm{~mm}$. It is formed by decomposition of sand stones due to various weathering actions. Fine aggregate prevents shrinkage of the mortar and concrete. The specific gravity and fineness modulus of coarse aggregate were 2.67 and 2.3.

Fine aggregate is an inert or chemically inactive material, most of which passes through a $4.75 \mathrm{~mm}$ IS sieve and contains no more than 5 percent of coarser material. It may be classified as follows:

(a) natural sand: fine aggregate that results from the natural disintegration of rocks and has been deposited by streams or glacial agencies;

(b) crushed stone sand: fine aggregate produced by crushing hard stone;

(c) crushed gravel sand: fine aggregate produced by crushing natural gravel.

It reduces the porosity of the final mass and considerably increases its strength. Usually, natural river sand is used as a fine aggregate. However, at places, where natural sand is not available economically, finely crushed stone may be used as a fine aggregate.

2.1.5. Coarse Aggregate. Coarse aggregate consists of naturally occurring materials such as gravel, or it results from the crushing of parent rock, to include natural rock, slags, expanded clays and shales (lightweight aggregates), and other approved inert materials with similar characteristics, having hard, strong, and durable particles, conforming to the specific requirements of this section.

According to the Indian standards, crushed angular aggregate passes through $20 \mathrm{~mm}$ IS sieve and entirely retains $10 \mathrm{~mm}$ IS sieve. The specific gravity and fineness modulus of coarse aggregate were 2.60 and 5.95 . 
2.1.6. Light Expanded Clay Aggregate (LECA). LECA is shown in Figure 1(c). it has strong resistance against alkaline and acidic substances and $\mathrm{pH}$ of nearly 7 makes it neutral in chemical post reaction with concrete. Lightness, insulating, durability, nondecomposability, structural stability, and chemical neutrality features are collected in LECA as the best light weight aggregate for flooring and roofing. The size of the aggregate is $10 \mathrm{~mm}$ and the maximum density is less than or equal to $480 \mathrm{Kg} / \mathrm{m}^{3}$. LECA consists of small, strong, light weight, and thermally insulating particles of burnt clay. LECA which is an environment-friendly and entirely natural product is indestructible, noncombustible, and impervious to attack by dry-rot, wet-rot, and insects. Lightweight concrete is generally classified into two types: aerated concrete (or foamed concrete) and lightweight aggregate concrete. The aerated concrete has very light weight and low thermal conductivity. However, an autoclaving process is essential to obtain a certain level of strength, which requires a special manufacturing plant and consumes very high energy. In contrast, lightweight aggregate concrete, which is manufactured without an autoclaving process, has higher strength but shows higher density and lower thermal conductivity of the concrete.

2.1.7. Conplast Admixture SP430 (G). Conplast SP430 (G) is used where a high degree of workability and its retention are required when delays in transportation or placing are likely or when high ambient temperatures cause rapid slump loss. It facilitates production of high quality concrete. Conplast SP430 (G) complies with the fact that it has been specially formulated to give high water reductions up to $25 \%$ without loss of workability or to produce high quality concrete of reduced permeability. Cohesion is improved due to dispersion of cement particles, thus minimizing segregation and improving surface finish. The optimum dosage is best determined by site trials with the concrete mix which enables the effects of workability, strength gain, or cement reduction to be measured. This type of ingredients is added in concrete to give it certain improved qualities or to change different physical properties in its fresh and hardened stages. Optimum dosage range of cement is $0.6-1.5$ liters $/ 100 \mathrm{~kg}$. The addition of an admixture may improve the concrete with respect to its strength, hardness, workability, water resisting power, and so forth.

2.1.8. Structural Specification of Beam. The structural specification of the beam is having top reinforcement diameter of $8 \mathrm{~mm}$, bottom reinforcement diameter of $12 \mathrm{~mm}$, and $6 \mathrm{~mm}$ stirrups (Figure 2). Total length of beam utilized for deflection is 1 meter. This specification is used in a concrete structure, and the whole process is done in the specification of a concrete.

2.1.9. Structural Light Weight Concrete. The concrete is made with a light weight coarse aggregate. Light weight aggregates generally require wetting prior to use to achieve a high degree of saturation. The primary use of structural light weight concrete is to reduce the dead load of a concrete structure.

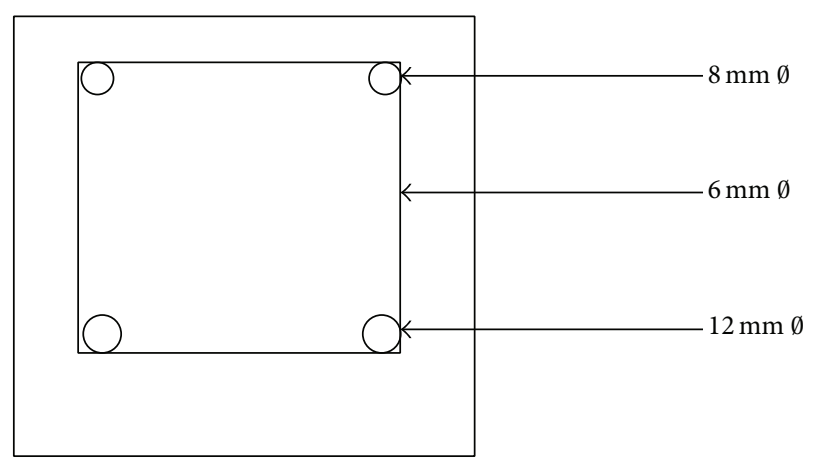

FIGURE 2: Cross section of beam.

In ordinary concrete different gradation of aggregates affects the required amount of water. Addition of some fine aggregates results in an increase in required amount of water. This increase of water reduces concrete strength unless the amount of cement in the same time increases. Amount of coarse aggregate and its biggest size depend on the required workability of concrete mixture. Also in light weight concrete, this result exists among the gradation, requested amount of water, and obtained concrete strength, but there are other factors that must be paid some attention. In most light weight aggregates as the size of aggregate increases the strength and bulk density of the aggregate decrease. Using very big size light weight aggregate with a lower strength results in a lower strength of the light weight concrete; therefore, biggest size of the light weight aggregate must be limited to $25 \mathrm{~mm}$ at most.

\section{Methodology}

Concrete mix proportion for $\mathrm{M}_{20}$ grade was obtained based on the guidelines according to Indian standard specifications (IS: 456-2000 and IS: 10262-1982). In this study, experimental investigation on concrete mix $\mathrm{M}_{20}$ is done by replacement of cement with fly ash, fine aggregate with bottom ash, and coarse aggregate with light expanded clay aggregate (LECA) at the rates of $5 \%, 10 \%, 15 \%, 20 \%, 25 \%, 30 \%$, and $35 \%$, respectively. For increasing the strength in cement, these materials are to be added. In the experimental investigation, the concrete cube or cylinder is used to analyze the properties of the OPC with all materials. Their compressive strength and split tensile strength of concrete have been discussed for 7 days, 28 days, 56 days and flexural strength of beam has been discussed for 7,28 , and 56 days depending on the optimum dosage of replacement in compressive strength and split tensile strength of concrete. Generally, fly ash and bottom ash have similar physical and chemical properties as compared to ordinary Portland cement (OPC) and fine aggregate, and there are not a lot of deviations for replacing each other. In this scenario, light expanded clay aggregate (LECA) has been replaced with coarse aggregate by its volume basis because density of each material is not the same as that of the other material and it is not possible to replace it by its weight basis. To increase the workability of concrete super plasticizer was added. 
TABLE 1: Mechanical properties of concrete.

\begin{tabular}{|c|c|c|c|c|c|c|c|c|}
\hline \multirow{2}{*}{$\begin{array}{l}\text { Percentage } \\
\text { replacement }\end{array}$} & \multirow{2}{*}{$\begin{array}{l}\text { Dry weight of specimen } \\
\text { (cube) in } \mathrm{Kg} / \mathrm{m}^{3}\end{array}$} & \multicolumn{3}{|c|}{$\begin{array}{l}\text { Compressive strength } \\
\text { of concrete }\left(\mathrm{N} / \mathrm{mm}^{2}\right)\end{array}$} & \multirow{2}{*}{$\begin{array}{l}\text { Dry weight of specimen } \\
\text { (cylinder) in } \mathrm{Kg}\end{array}$} & \multicolumn{3}{|c|}{$\begin{array}{l}\text { Split tensile strength } \\
\text { of concrete }\left(\mathrm{N} / \mathrm{mm}^{2}\right)\end{array}$} \\
\hline & & 7 days & 28 days & 56 days & & 7 days & 28 days & 56 days \\
\hline 0 & 9.45 & 17.96 & 26.93 & 26.95 & 14.35 & 1.60 & 2.54 & 2.57 \\
\hline 5 & 9.18 & 17.94 & 26.89 & 26.97 & 14.20 & 1.53 & 2.52 & 2.59 \\
\hline 10 & 8.89 & 17.17 & 25.73 & 25.76 & 13.85 & 1.5 & 2.32 & 2.33 \\
\hline 15 & 8.54 & 16.06 & 24.09 & 24.11 & 13.60 & 1.44 & 2.17 & 2.18 \\
\hline 20 & 8.41 & 13.41 & 20.10 & 20.13 & 13.40 & 1.4 & 2.11 & 2.12 \\
\hline 25 & 8.31 & 11.32 & 16.96 & 16.97 & 13.15 & 1.35 & 2.05 & 2.06 \\
\hline 30 & 8.24 & 10.19 & 15.26 & 15.23 & 12.72 & 1.31 & 1.96 & 1.98 \\
\hline 35 & 8.13 & 9.73 & 14.57 & 14.58 & 12.34 & 1.26 & 1.90 & 1.92 \\
\hline
\end{tabular}

The ratio of concrete mix $\mathrm{M}_{20}$ grade was $1: 1.42: 3.3$. Controlled concrete of $\mathrm{M}_{20}$ grade was made with $0 \%$ replacement of fly ash, bottom ash, and light expanded clay aggregate (LECA) in each mix and their compressive strength and split tensile strength of concrete have been discussed for 7,28, and 56 days and flexural strength of concrete has been discussed for 7,28 , and 56 days. In this connection replacement of cement with fly ash, fine aggregate with bottom ash, and coarse aggregate with light expanded clay aggregate (LECA) at the rates of $5 \%, 10 \%, 15 \%, 20 \%, 25 \%, 30 \%$, and $35 \%$ in each mix was conducted and their compressive strength and split tensile strength of concrete were discussed for 7 days, 28 , days, 56 days and flexural strength of beam for 7, 28 and 56 days depends on the optimum dosage of replacement in compressive strength and split tensile strength of concrete.

Water absorption of light weight aggregate with too much pores is much more than ordinary aggregates (river aggregates). Determination of amount of water absorption in these kinds of aggregates is difficult because of the varying amounts of absorbed water. LECA aggregate produced rotary kiln, and because of its smooth surface, water absorption of LECA aggregate is nearly equal to or somewhat more than that of ordinary aggregate; therefore, design of light weight concrete mixture with LECA aggregate is as difficult as that of ordinary aggregate. For determining the amount of each ingredient in light weight concrete mixture (along with the amount of absorbed water in light weight aggregates, especially those with too much pores with rough and angular surface, by making different mixtures) one can use the common design methods of ordinary concrete mixture.

\section{Result and Discussion}

From Table 1 it is observed that for control specimen strength of the concrete increases with respect to age. For 5\% replacement of cement with fly ash, fine aggregate with bottom ash, and coarse aggregate with LECA the compressive strength of concrete is the same as that of control concrete. The split tensile strength slightly decreases at early age and it attains the same strength of control concrete at 56 days.

It is also observed that when the replacement of material increases, the compressive strength and split tensile strength decrease. The dry weight of cube and cylinder specimens decreases with respect to more replacements of materials.

4.1. Strength Analysis with respect to Age of Concrete. In Table 1 compressive strength of concrete and split tensile strength of concrete are evaluated by means of various mixing percentage applied to form cubic dry weight specimen and cylindrical dry weight specimen, respectively, with respect to different days.

For $\mathrm{M}_{20}$ grade concrete, the following proposition percentage mixing is taken into account for various dry weight specimens applied to cubic shape for finding compressive strength with respect to 7,28 , and 56 days such that dry weight specimen was applied to cylinder shape with respect to aforementioned days to find split tensile strength. For both strengthening analyses $\mathrm{M}_{20}$ grade type concrete is utilized. From Table 1 the stated results show that mixing percentage increases with decrease in specimen weight, but in strength point of view the increase in mixing percentage will certainly reduce the strength attain in both compressive strength and split tensile strength, or on other hand when the mixing proportion does not take part in this (i.e., when it is "Zero"), then the weight of the specimen is high compared to the fact that to the mixing proportion which is blended. In both cases of strength analysis extension of days will certainly the strength of projection of the those analyses as clearly statedin Table 1 .

Figure 3 shows the cube compressive strength analysis that takes part in three stages of consecutive days 7, 28, and 56 based on various mixing propositions. The attained results show that the process done for consecutive 56-day test results shows better compressive strength on nonmixing whereas case of gradual increasing in mixing percentage will certainly reduce the compressive strength of all testing days specimens. In case of weight the increase in mixing percentage will reduce the weight.

Figure 4 shows the cylindrical shape split tensile strength analysis for different days. Moreover, in this split tensile strength analysis the increase in mixing percentage will certainly reduce the weight and will also reduce the strengthening factors. 


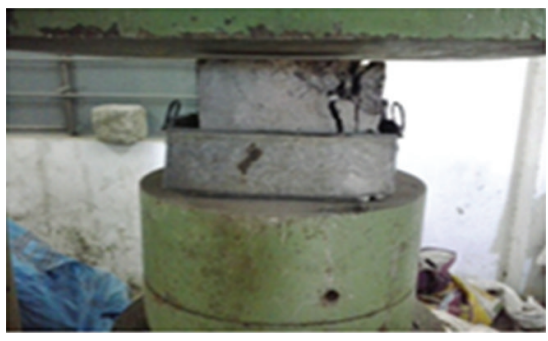

(a) Compression test on cube

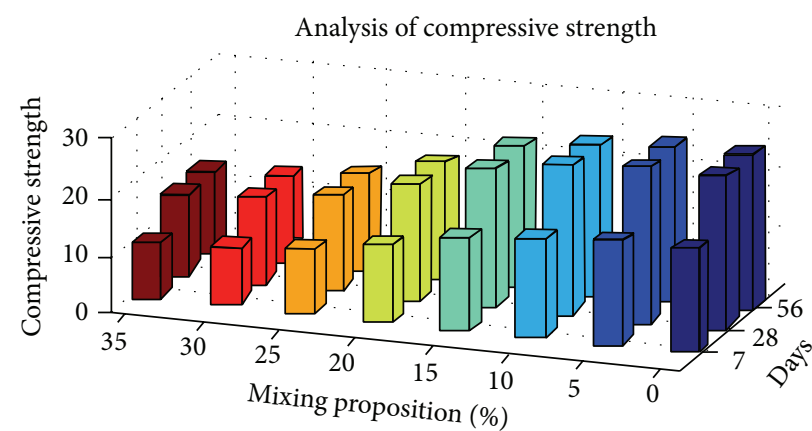

(b) Compressive strength

Figure 3: Compressive strength.

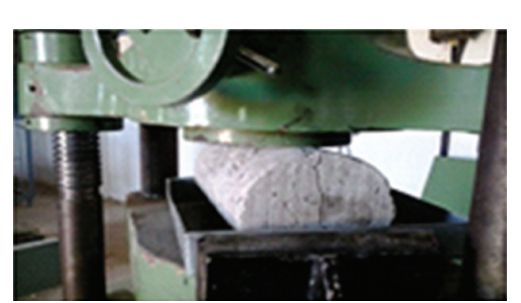

(a) Split tensile strength on cylinder

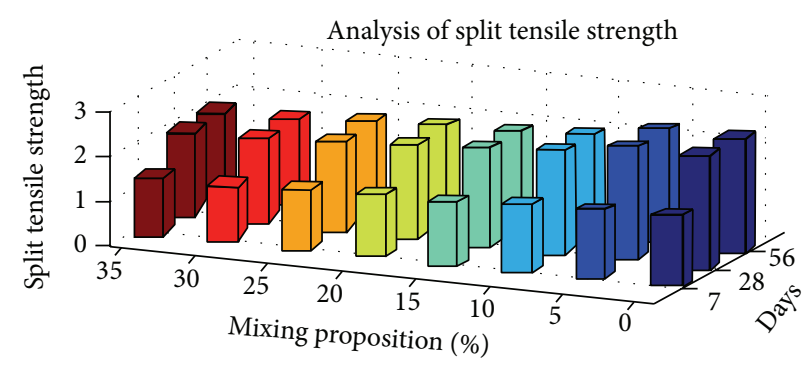

(b) Split tensile strength

FIGURE 4: Split tensile strength.

From the aforementioned two shapes (cubic and cylinder shapes) the projected result analyses of the compressive strength and split tensile strength analyses are almost similar. Let us see the exponential behaving and its regression equation for compressive strength and split tensile strength.

Exponential Graph Based on Mixing Percentage for Compressive Strength. Figure 5 simulates regression based exponential curve for compressive strength analysis for various mixing percentages. From Figure 5 consecutive specimen test for 28 and 56 days produced almost the same values, whereas exponential equation of compressive strength in Table 2 ranges from 0 to $35 \mathrm{~N} / \mathrm{mm}^{2}$ in all four evaluation equations causing an increase in mixing percentage which will reduce all four parameters of dry weight for 7,28 , and 56 days. In the four cases other than dry weight the performance reduces, whereas in case of dry weight increase in mixing percentage will certainly reduce the weight.

Exponential Graph Based on Mixing Percentage for Split Tensile Strength. In Figure 6 the graph shows the exponential variation of dry weight and for various consecutive days such as 7,28 , and 56 . In this dry weight having tensile strength of nearly $14.468 e^{-0.0004 x}, x$ denotes mixing percentage; in addition to this, all other consecutive days based exponential curve get reduced and they are almost similar to each other having range of $(0-15) \mathrm{N} / \mathrm{mm}^{2}$.

Table 2 includes particulars of dry weight and specimen for consecutive days such as 7,28 , and 56 days starting from

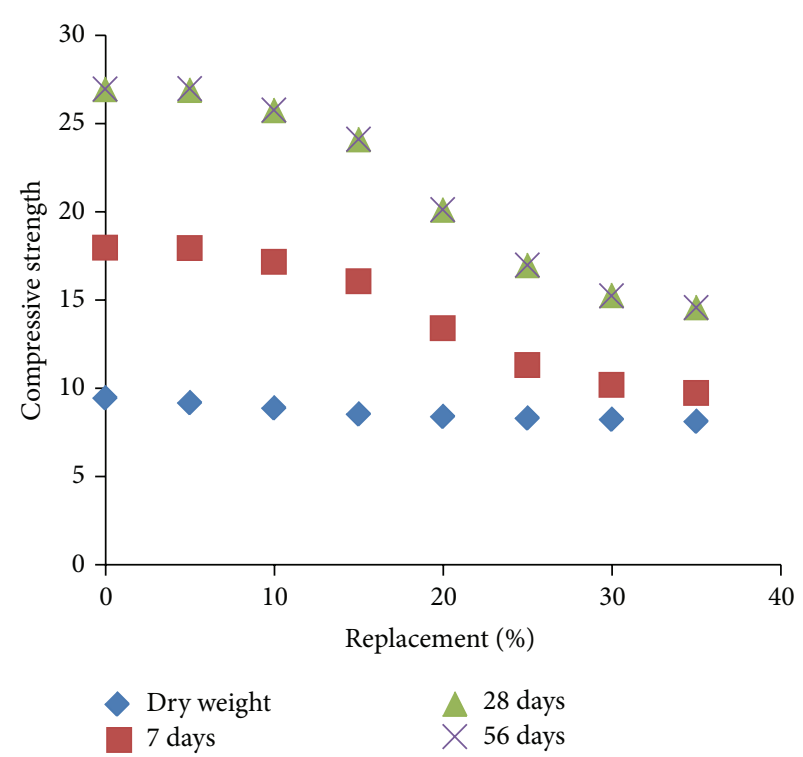

FIGURE 5: Exponential graph for compressive strength and dry weight.

dry weight in compressive strength which starts with lower regression values and keeps on increasing for 7, 28, and 56 days, whereas in the case of split tensile strength dry weight regression value is greater than the compressive strength regression value. In case of days analysis the regression values 
TABLE 2: Regression equation for compressive and tensile strength.

\begin{tabular}{lcc}
\hline Particulars & $\begin{array}{c}\text { Exponential } \\
\text { regression for } \\
\text { compressive strength }\end{array}$ & $\begin{array}{c}\text { Exponential } \\
\text { regression for split } \\
\text { tensile strength }\end{array}$ \\
\hline Dry weight & $Y=9.309 e^{-0.004 x}$ & $Y=14.468 e^{-0.0004 x}$ \\
7 days & $Y=19.746 e^{-0.02 x}$ & $Y=1.5948 e^{-0.007 x}$ \\
28 days & $Y=29.61 e^{-0.02 x}$ & $Y=2.5476 e^{-0.009 x}$ \\
56 days & $Y=29.666 e^{-0.02 x}$ & $Y=2.5827 e^{-0.009 x}$ \\
\hline
\end{tabular}

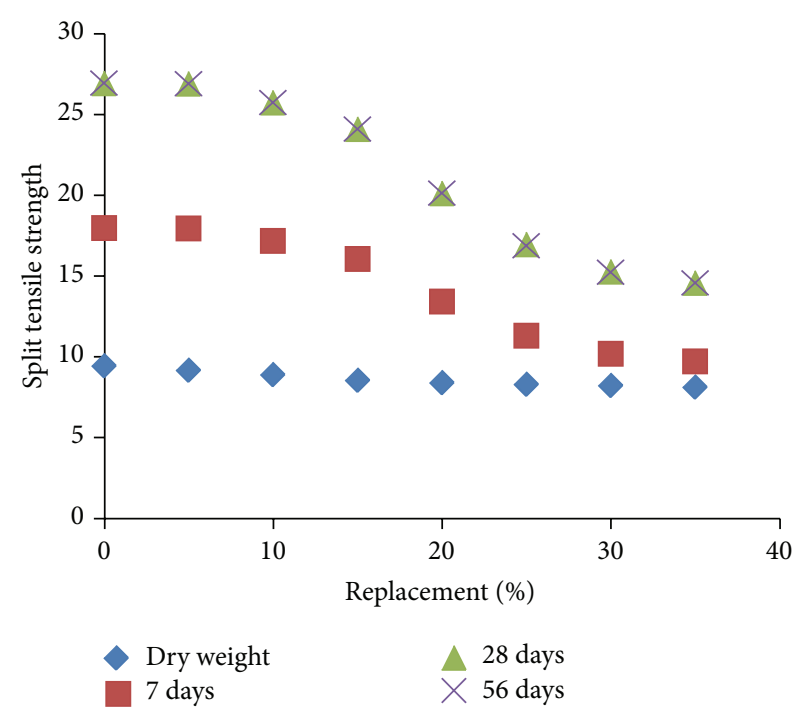

FIGURE 6: Exponential graph for split tensile strength and dry weight.

TABLE 3: Flexural strength of beam.

\begin{tabular}{lcccc}
\hline \multirow{2}{*}{ Specimen type } & $\begin{array}{l}\text { Dry weight of } \\
\text { specimen in Kg }\end{array}$ & \multicolumn{3}{c}{$\begin{array}{c}\text { Flexural strength } \\
\text { of beam }\left(\mathrm{N} / \mathrm{mm}^{2}\right)\end{array}$} \\
& 5 days & 28 days & 56 days \\
\hline Control & 56.25 & 16.65 & 24.7 & 25.83 \\
5\% replacement & 55.13 & 17.58 & 26.03 & 27.13 \\
\hline
\end{tabular}

increase with the increase in the number of days in the tensile strength regression analysis model.

4.2. Flexural Strength Analysis. One measure of the tensile strength of concrete is flexural strength. It is the computation of an unreinforced concrete beam or slab to resist failure in bending (Figure 7). Designers of pavements use a theory based on flexural strength; therefore laboratory mix design based on flexural strength test may be needed. In Table 3 percentages of replacement of cement with fly ash, fine aggregate with bottom ash, and coarse aggregate with light expanded clay aggregate (LECA) at the rates of $0 \%$ and $5 \%$ are employed.

From Table 3 the results show that the percentages of replacement of cement with fly ash, fine aggregate with bottom ash, and coarse aggregate with light expanded clay aggregate (LECA) at the rate of $5 \%$ perform better than

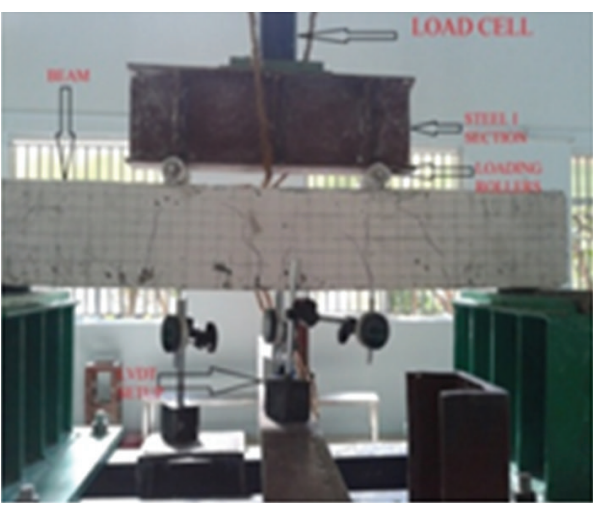

Figure 7: Flexural strength on beam.

TABLE 4: Load versus deflection of control specimen.

Deflection $(\mathrm{mm})$

\begin{tabular}{|c|c|c|c|}
\hline \multirow[t]{2}{*}{ Load $(\mathrm{KN})$} & \multicolumn{3}{|c|}{ ( $0 \%$ replacement of fly ash, bottom ash, and LECA) } \\
\hline & Left & Middle & Right \\
\hline 0 & 0 & 0 & 0 \\
\hline 3.92 & 0.21 & 0.252 & 0.194 \\
\hline 7.84 & 0.284 & 0.324 & 0.284 \\
\hline 11.77 & 0.42 & 0.54 & 0.5 \\
\hline 15.69 & 0.58 & 0.756 & 0.631 \\
\hline 19.62 & 0.745 & 0.978 & 0.785 \\
\hline 23.54 & 1.031 & 1.234 & 1.016 \\
\hline 27.46 & 1.202 & 1.512 & 1.198 \\
\hline 31.39 & 1.382 & 1.962 & 1.391 \\
\hline 35.32 & 1.594 & 2.264 & 1.624 \\
\hline 39.24 & 1.828 & 2.789 & 1.841 \\
\hline 43.16 & 1.972 & 2.936 & 1.986 \\
\hline 47.03 & 2.052 & 3.142 & 2.034 \\
\hline 51.01 & 2.21 & 3.364 & 2.198 \\
\hline 54.94 & 2.352 & 3.724 & 2.346 \\
\hline 58.86 & 2.41 & 4.125 & 2.402 \\
\hline 62.78 & 2.57 & 4.589 & 2.556 \\
\hline 66.71 & 2.625 & 4.96 & 2.618 \\
\hline 70.63 & 2.715 & 5.146 & 2.708 \\
\hline 74.56 & 2.86 & 5.476 & 2.846 \\
\hline 78.48 & 3.14 & 5.742 & 3.008 \\
\hline 82.41 & 3.46 & 5.969 & 3.396 \\
\hline 86.32 & 4.19 & 6.326 & 4.07 \\
\hline
\end{tabular}

$0 \%$. This dry weight of the specimen is reduced to $5 \%$ and moreover flexural strength of the beam for 7 days is $1.67 \%$ greater than $0 \%$, and in 28 days it is $1.52 \%$ greater than $0 \%$ and in 56 days it is $1.46 \%$ greater than $0 \%$.

In Table 4 test load is applied from 0 to $86.32 \mathrm{KN}$ at various intervals and we tried to find the deflection of $\mathrm{M}_{20}$ in the left, middle, and right of the beam. The deflections in all levels are gradually increased when the applied 
TABLE 5: Load versus deflection of beam with optimum mix.

\begin{tabular}{|c|c|c|c|}
\hline \multirow[t]{2}{*}{ Load (KN) } & \multicolumn{3}{|c|}{$\begin{array}{c}\text { Deflection }(\mathrm{mm}) \\
\text { (5\% replacement of fly ash, bottom ash, and LECA) }\end{array}$} \\
\hline & Left & Middle & Right \\
\hline 0 & 0 & 0 & 0 \\
\hline 3.92 & 0.205 & 0.25 & 0.207 \\
\hline 7.84 & 0.29 & 0.321 & 0.285 \\
\hline 11.77 & 0.45 & 0.536 & 0.458 \\
\hline 15.69 & 0.54 & 0.76 & 0.535 \\
\hline 19.62 & 0.81 & 1.02 & 0.793 \\
\hline 23.54 & 1.037 & 1.231 & 1.037 \\
\hline 27.46 & 1.198 & 1.507 & 1.20 \\
\hline 31.39 & 1.375 & 1.96 & 1.379 \\
\hline 35.32 & 1.584 & 2.265 & 1.582 \\
\hline 39.24 & 1.815 & 2.785 & 1.816 \\
\hline 43.16 & 2.05 & 2.937 & 2.02 \\
\hline 47.03 & 2.07 & 3.14 & 2.05 \\
\hline 51.01 & 2.15 & 3.361 & 2.17 \\
\hline 54.94 & 2.38 & 3.72 & 2.38 \\
\hline 58.86 & $2 . .46$ & 4.118 & $2 . .47$ \\
\hline 62.78 & 2.56 & 4.587 & 2.54 \\
\hline 66.71 & 2.61 & 4.95 & 2.615 \\
\hline 70.63 & 2.69 & 5.143 & 2.69 \\
\hline 74.56 & 2.84 & 5.472 & 2.838 \\
\hline 78.48 & 3.11 & 5.74 & 3.115 \\
\hline 82.41 & 3.4 & 5.965 & 3.4 \\
\hline 86.32 & 4.05 & 6.321 & 4.05 \\
\hline
\end{tabular}

load increases. The average deflection in the left of the beam is about $1.71 \mathrm{~mm}$, whereas in middle deflection it is about $2.961 \mathrm{~mm}$ and in right side the deflection is about $1.810 \mathrm{~mm}$.

In Table 5 test load is applied in $\mathrm{M}_{20}$ from 0 to $86.32 \mathrm{KN}$ at various intervals and the deflections were measured in the left, middle, and right of the beam. The deflections in all levels are gradually increased when the applied load increases. The average deflection in the left of the beam is about $1.782 \mathrm{~mm}$, whereas in middle the deflection is about $2.960 \mathrm{~mm}$ and in right side the deflection is about $1.78 \mathrm{~mm}$. From Table 5 it is proved that the deflection of $5 \%$ replacement of flexural strength is higher than $0 \%$ replacement.

In Figure $8, \mathrm{M}_{20}$ grade $0 \%$ and $5 \%$ replacement of fly ash, bottom ash, and LECA are analysed to test their flexural strength. In the graph it is clearly stated that when load increases the deflection also increases for $0 \%$ and for $5 \%$ amid(23), and average deflection values are similar to both $0 \%$ and $5 \%$ but $0 \%$ they are slightly higher than $5 \%$, whereas this graph have sum of all deflection levels in 1 unit. For example, here, the fact that the considered length of beam is said to be 1 meter for expermental investigation by appling " $x$ " unit of load will cause the amount of deflection in both cases $(0 \%$ and $5 \%$ ) in respect of increase in load to certainly increase the deflection.

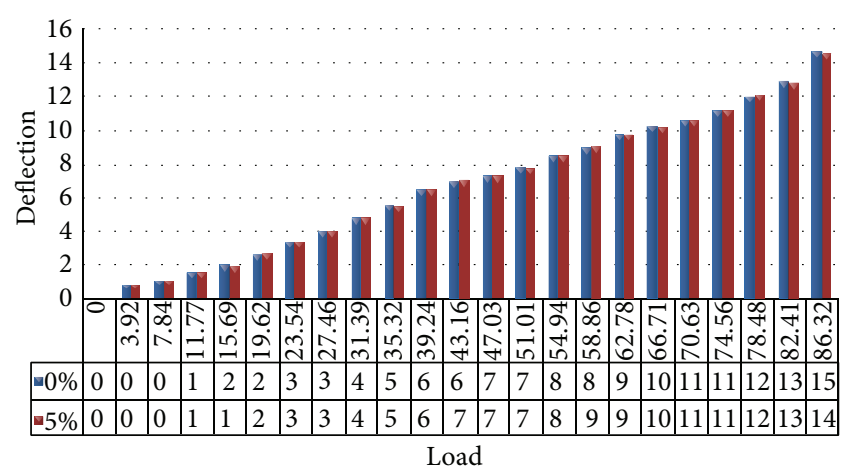

FIGURE 8: Load versus deflection.

\section{Conclusion}

The paper attains the highest possible strength for LECA concrete while noting the advanced technology in producing light weight concrete. The results show that $5 \%$ replacement of cement with fly ash, fine aggregate with bottom ash, and coarse aggregate with light expanded clay aggregate (LECA) was found to be good performance in compressive strength, split tensile strength, and flexural strength of beam in 56 days when compared with 28 days strength. At the same time 28 days strength also approximately equals normal conventional concrete; that is, $0 \%$ replacement and dry weight of specimen have been reduced. In future, soft computing techniques will lead with core areas us to attain better performance in short interval of time as the time is the major factor involved in this research work.

\section{Conflict of Interests}

The authors declare that there is no conflict of interests regarding the publication of this paper.

\section{References}

[1] V. Patel and N. Shah, "A survey of high performance concrete developments in civil engineering field," Open Journal of Civil Engineering, vol. 3, no. 2, pp. 69-79, 2013.

[2] M. M. Al Bakri, H. Mohammed, H. Kamarudin, I. K. Niza, and Y. Zarina, "Review on fly ash-based geopolymer concrete without Portland Cement," Journal of Engineering and Technology Research, vol. 3, no. 1, pp. 1-4, 2011.

[3] C. Marthong and T. P. Agrawal, "Effect of fly ash additive on concrete properties," Journal of Engineering Research and Applications, vol. 2, no. 4, pp. 1986-1991, 2012.

[4] A. Charif, M. J. Shannag, and S. Dghaither, "Ductility of reinforced lightweight concrete beams and columns," Latin American Journal of Solids and Structures, vol. 11, no. 7, pp. 12511274, 2014.

[5] C. Meng and Z. Jin-Yang, "Studies on lightweight high-strength shotcrete," in Proceedings of the 4th International Conference on Digital Manufacturing and Automation (ICDMA '13), pp. 12311234, June 2013.

[6] A. A. Adegbola and M. J. Dada, "Development of mathematical equations and programs for the optimization of concrete mix 
designs," Journal of Science \& Technology, vol. 5, no. 11, pp. 1-18, 2012.

[7] F. N. Okonta, "Frictional resistance of coal dust fouled uniformly graded aggregates," International Journal of the Physical Sciences, vol. 7, no. 23, pp. 2960-2970, 2012.

[8] H. K. Kim, J. H. Jeon, and H. K. Lee, "Workability, and mechanical, acoustic and thermal properties of lightweight aggregate concrete with a high volume of entrained air," Construction and Building Materials, vol. 29, pp. 193-200, 2012.

[9] O. Gencel, F. Koksal, C. Ozel, and W. Brostow, "Combined effects of fly ash and waste ferrochromium on properties of concrete," Journal of Construction and Building Materials, vol. 29, pp. 633-640, 2012.

[10] M. Al Bakri, H. Kamarudin, M. Bnhussain, I. Khairul Nizar, A. R. Rafiza, and Y. Zarina, "Microstructure of different $\mathrm{NaOH}$ molarity of fly ashbased green polymeric cement," Journal of Engineering and Technology Research, vol. 3, no. 2, pp. 44-49, 2011.

[11] A. U. Abubakar and K. S. Baharudin, "Properties of concrete using tanjung bin power plant coal bottom ash and fly ash," Journal of Sustainable Construction Engineering \& Technology, vol. 3, no. 2, pp. 1-14, 2012.

[12] R. J. Haynes, "Reclamation and revegetation of fly ash disposal sites—challenges and research needs," Journal of Environmental Management, vol. 90, no. 1, pp. 43-53, 2009.

[13] A. Sarkar, R. Rano, G. Udaybhanu, and A. K. Basu, "A comprehensive characterisation of fly ash from a thermal power plant in Eastern India," Fuel Processing Technology, vol. 87, no. 3, pp. 259-277, 2006.

[14] T. Uygunolu, I. B. Topcu, O. Gencel, and W. Brostow, “The effect of fly ash content and types of aggregates on the properties of pre-fabricated concrete interlocking blocks (PCIBs)," Construction and Building Materials, vol. 30, pp. 180-187, 2012.

[15] T. Mehmannavaz, M. Ismail, S. Radin Sumadi, M. A. Rafique Bhutta, M. Samadi, and S. M. Sajjadi, "Binary effect of fly ash and palm oil fuel ash on heat of hydration aerated concrete," The Scientific World Journal, vol. 2014, Article ID 461241, 6 pages, 2014.

[16] M. R. Moini, A. Lakizadeh, and M. Mohaqeqi, "Effect of mixture temperature on slump flow prediction of conventional concretes using artificial neural networks," Australian Journal of Civil Engineering, vol. 10, no. 1, pp. 87-98, 2012.

[17] I. T. Yusuf and Y. A. Jimoh, "The transfer models of compressive to tensile, flexural and elastic properties of palm kernel shell concrete," Journal of Engineering, vol. 9, pp. 195-200, 2013.

[18] A. Golroo and S. L. Tighe, "Pervious concrete pavement performance modelling using the bayesian statistical technique," Journal of Transportation Engineering, vol. 138, no. 5, pp. 603609, 2012.

[19] A. Sivakumar and P. Gomathi, "Pelletized fly ash lightweight aggregate concrete: a promising material," Journal of Civil Engineering and Construction Technology, vol. 3, no. 2, pp. 4248, 2012.

[20] U. A. Abdulhameed and B. K. Salleh, "Compressive strength of high volume coal bottom ash utilization as fine aggregate in fly ash-cement blended concrete," Journal of Engineering \& Technology Sciences, vol. 1, no. 4, pp. 226-239, 2013.

[21] J. H. Pramana, A. A. A. Samad, A. M. A. Zaidi, and F. V. Riza, "Preliminary study on lightweight concrete under ballistic loading," European Journal of Scientific Research, vol. 44, no. 2, pp. 285-299, 2010.
[22] J. J. Del Coz Díaz, F. P. Álvarez-Rabanal, O. Gencel et al., "Hygrothermal study of lightweight concrete hollow bricks: a new proposed experimental-numerical method," Journal of Energy and Buildings, vol. 70, pp. 194-206, 2014.

[23] E. Güneyisi, M. Gesoğlu, and S. Ipek, "Effect of steel fiber addition and aspect ratio on bond strength of cold-bonded fly ash lightweight aggregate concretes," Construction and Building Materials, vol. 47, pp. 358-365, 2013.

[24] P. Posi, C. Teerachanwit, C. Tanutong et al., "Lightweight geopolymer concrete containing aggregate from recycle lightweight block," Materials and Design, vol. 52, pp. 580-586, 2013.

[25] A. U. Abubakar and K. S. Baharudin, "Potential use of malaysian thermal power plants coal bottom ash in construction," Journal of Sustainable Construction Engineering \& Technology, vol. 3, no. 2, pp. 1-13, 2012. 

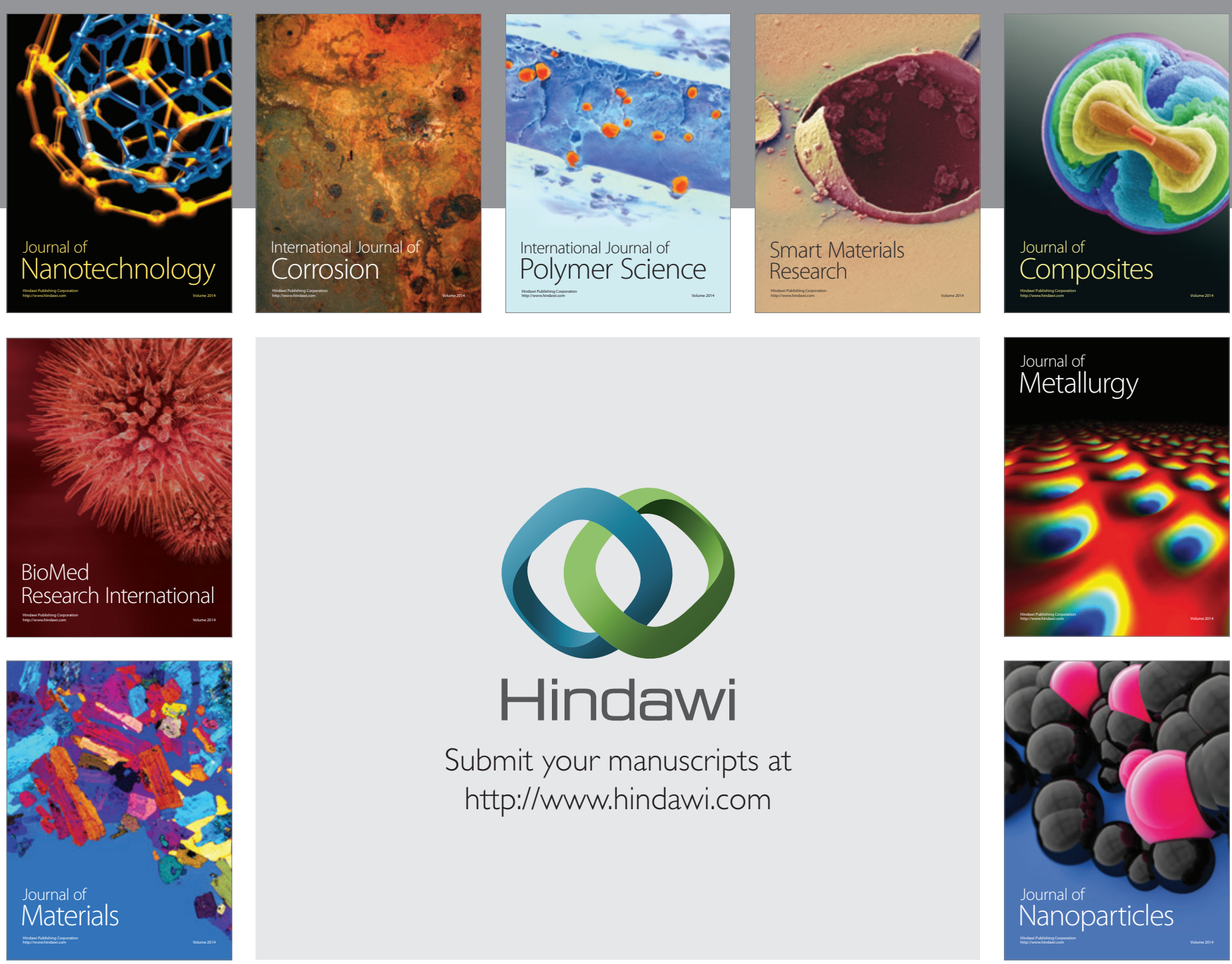

Submit your manuscripts at http://www.hindawi.com
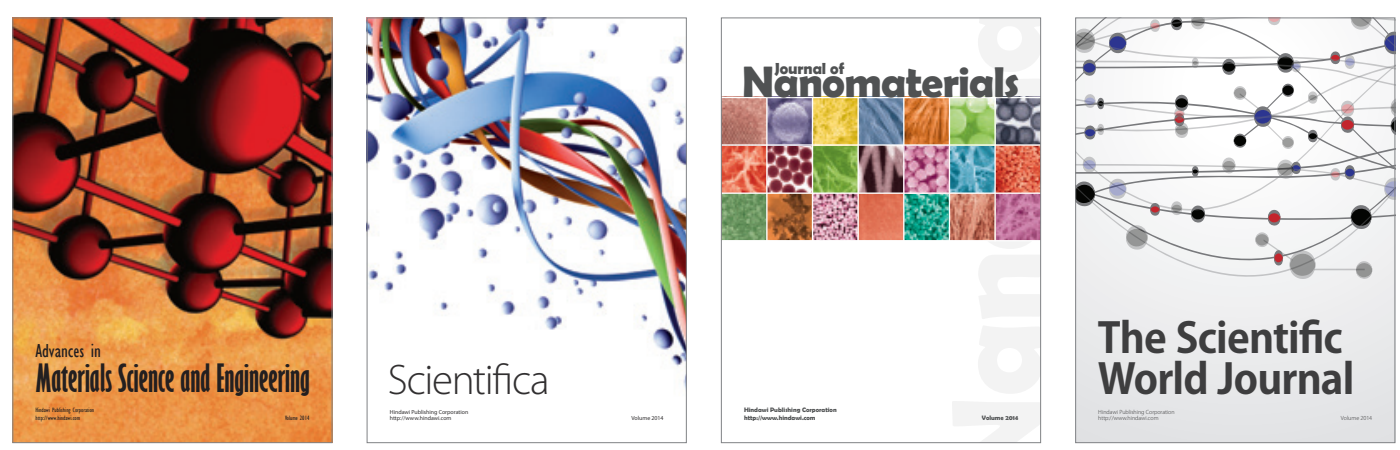

\section{The Scientific World Journal}
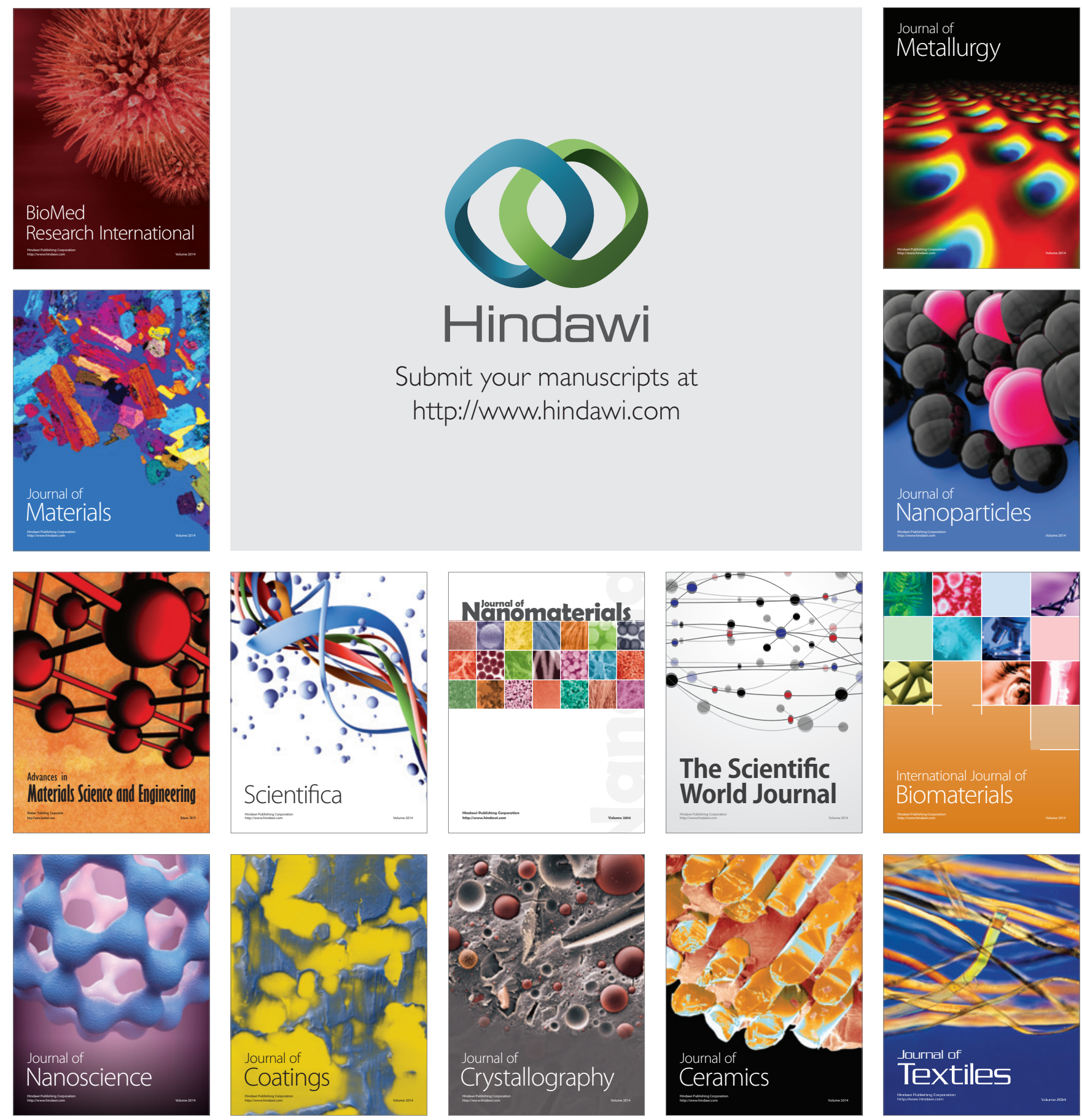